\title{
GERMINAÇÃO E SUPERAÇÃO DE DORMÊNCIA DE SEMENTES DE ESPÉCIES FLORESTAIS
}

Marcone Moreira Santos ${ }^{1}$, Rodrigo de Oliveira Lara ${ }^{2}$, Lorena Leão de Jesus ${ }^{3}$

${ }^{1}$ Doutorando em Ciência Florestal da Universidade Federal de Viçosa (UFV) (marconemoreirasantos@hotmail.com) Viçosa- Brasil

${ }^{2}$ Mestre em Ciência Florestal pela Universidade Federal dos Vales do Jequitinhonha e Mucuri (UFVJM) Diamantina- Brasil

${ }^{3}$ Mestre em Produção Vegetal pela Universidade Federal dos Vales do Jequitinhonha e Mucuri (UFVJM) Diamantina- Brasil

Recebido em: 08/09/2015 - Aprovado em: 14/11/2015 - Publicado em: 01/12/2015 DOI: http://dx.doi.org/10.18677/Enciclopedia_Biosfera_2015_170

Objetivou-se com o trabalho, verificar existência ou não de dormência tegumentar e estabelecer uma metodologia para sua superação (caso ocorra) em sementes de canafístula, pau- jacaré, fedegoso, vinhático e pau-santo. Foram testados os seguintes tratamentos para superação da dormência: sem tratamento prévio (Controle); escarificação com ácido sulfúrico P.A. por 5 minutos $\left(\mathrm{H}_{2} \mathrm{SO}_{4}\right)$; imersão em água a $100^{\circ} \mathrm{C}$ por 5 minutos e embebição em água em temperatura ambiente por 24 horas. Para o pau santo, não se utilizou o tratamento de escarificação em ácido sulfúrico. A escarificação química se mostrou eficiente para promover a quebra da dormência de canafístula e vinhático. Nenhum dos tratamentos pré-germinativos avaliados se mostrou eficaz para promover a quebra de dormência do Fedegoso. Não foi observada dormência tegumentar para sementes de pau-santo e pau-jacaré, no entanto, a embebição em água por 24 horas favorece a germinação de ambas as espécies.

PALAVRAS-CHAVE: Dormência tegumentar, Escarificação e Embebição.

\section{GERMINATION AND OVERCOMING DORMANCY IN SPECIES SEEDS FOREST}

\begin{abstract}
The objective of the study was to verify whether cutaneous numbness is present and establish a methodology to overcome them (in the event) in seed tariff alligatorin seeds of Canafístula, Pau jacaré, Fedegoso, Vinhático and Pau Santo. The following treatments were used to overcome dormancy: untreated group (control); PA scarification with sulfuric acid for 5 minutes (H2SO4); immersion in water at $100^{\circ} \mathrm{C}$ $\left(212^{\circ} \mathrm{F}\right)$ for 5 minutes and soaking in water at room temperature for 24 hours. It were not used the treatment of scarification in sulfuric acid for Pau Santo. The chemical scarification proved efficient to break the dormancy of canafístula and vinhatico. None of the pre-germination treatments evaluated was were (plural, nao singular) effective to promote of the breaking of dormancy breaking in Fedegoso seeds. There
\end{abstract}


was no numbness cutaneous for Pau Santo and Pau jacare, however, the immersion in water for 24 hours encourages germination of both pecies.

KEYWORDS: Cutaneous numbness, Scarification and Soaking.

\section{INTRODUÇÃO}

A Mata Atlântica, bioma extremamente diverso, hoje é um ambiente ameaçado devido ao alto índice de degradação iniciado a partir do processo de colonização no Brasil (RIBEIRO et al., 2009). Dentre as diversas espécies florestais presentes neste bioma destacam-se a Piptadenia gonoacantha (Mart.), a Senna multijuga e a Senna macranthera, conhecidas respectivamente como pau-jacaré, canafístula e fedegoso. O pau-jacaré é utilizado na recomposição de áreas degradadas e preservação do meio ambiente (HERNÁNDEZ et al., 2012), a Canafístula na produção de madeira (SOUZA et al., 2013) e o fedegoso como planta ornamental e na arborização urbana (LORENZI, 2014).

Assim como a Mata atlântica, o cerrado brasileiro está entre os biomas de maior diversidade florística do planeta. Entretanto, as áreas nativas vêm sendo removidas em um ritmo acelerado e desordenado devido a ocupação das terras para a produção agrícola mecanizada, pecuária, empreendimentos de mineração e urbanização (CAMARGO et al., 2014). Além da canafístula e do fedegoso, espécies da mata atlântica também encontradas no cerrado, o vinhático (Plathymenia reticulata) e o pau-santo (Kielmeyera lathrophyton) são espécies importantes para o desenvolvimento da região. O vinhático apresenta uma madeira de alta qualidade e um grande potencial em recuperação de áreas degradadas (BRAGA et al., 2007) e o pau-santo é uma espécie utilizada na produção de cortiça, madeira, celulose, tanino e carvão (SOUZA, 1974).

Devido ao grande número de espécies nesses dois biomas ainda é muito limitado o conhecimento sobre a germinação, cultivo e potencialidade dessas espécies florestais, necessitando assim de mais estudos. Segundo BEWLEY \& BLACK (1994), a germinação engloba eventos que se iniciam com a absorção de água pela semente e termina com a elongação do eixo embrionário. Fisiologicamente falando o processo germinativo pode ser dividido em fases, como embebição, alongamento celular e divisão celular após protrusão radicular. Os fatores luz, temperatura, substrato e dormência são os que mais afetam o processo de germinação das sementes (CARVALHO \& NAKAGAWA, 2012).

Muitas espécies florestais possuem sementes que embora sendo viáveis e tendo todas as condições normalmente consideradas adequadas deixam de germinar, sendo denominadas dormentes e precisam de tratamentos especiais (CARVALHO \& NAKAGAWA, 2012). Mesmo que a dormência seja uma adaptação para sobrevivência das espécies a longo prazo, pois geralmente faz com que as sementes mantenham-se viáveis por maior período de tempo, sendo superadas em situações especiais (XAVIER et al., 2012), isto é inconveniente quando se deseja a multiplicação das espécies.

A dormência de sementes pode se manifestar de três formas: dormência imposta pelo tegumento, dormência embrionária e dormência devido ao desequilíbrio entre substâncias promotoras e inibidoras de germinação (BEWLEY \& BLACK, 1994). A dormência imposta pelo tegumento é um tipo de dormência física causada pela impermeabilidade dos tegumentos das sementes ou fruto à água. Esta é a mais recorrente entre as espécies vegetais, ocorrendo em 15 famílias das Angiospermas (BASKIN et al., 2000). 
A impermeabilidade do tegumento pode ser superada por meio da escarificação, que resulta na ruptura ou no enfraquecimento do tegumento permitindo a passagem de água e dando início ao processo germinativo (MAYER \& POLJAKOFF-MAYBER, 1989). Diversos métodos vem sendo utilizados com sucesso para a superação da dormência de espécies florestais, destacando-se a escarificação química (FREITAS et al., 2013; JÚNIOR et al., 2014), mecânica (SILVA et al., 2012; SANTOS et al., 2013), a imersão em água quente (ARAÚJO et al., 2012; ARRUDA et al., 2012) e imersão em água em temperatura ambiente (XAVIER et al., 2012).

Portanto, os estudos referentes a germinação e comportamento fisiológico das sementes de espécies florestais são fundamentais visando a produção de mudas para recomposição de áreas degradadas e implantação de florestas com fins produtivos. Diante do exposto, objetivou-se: verificar existência ou não de dormência tegumentar e estabelecer uma metodologia para sua superação (caso ocorra) em sementes de pau- jacaré (Piptadenia gonoacantha), canafístula (Senna multijuga), fedegoso (Senna macranthera), vinhático (Plathymenia reticulata) e pau-santo (Kielmeyera lathrophyton).

\section{MATERIAL E MÉTODOS}

\section{Coleta das sementes}

Os frutos foram coletados diretamente nas matrizes no período de agosto a outubro de 2012. Os frutos de canafístula, pau-jacaré e fedegoso, foram coletados no Campus Experimental do Moura, município de Curvelo, Minas Gerais. Os frutos de vinhático e pau-santo foram coletados no Parque Estadual do Biribiri, município de Diamantina, Minas Gerais. Posteriormente, foram levados ao laboratório de Sementes III do Centro Integrado de Propagação de Espécies Florestais (CIPEF), do Departamento de Engenharia Florestal (DEF) da Universidade Federal dos Vales do Jequitinhonha e Mucuri (UFVJM), onde as sementes foram extraídas manualmente, beneficiadas e colocadas em sacos plásticos até o momento da instalação dos experimentos.

\section{Grau de umidade}

No Laboratório de Sementes II do CIPEF, foram pesadas três repetições com cinco gramas de sementes para cada espécie. Posteriormente, foram colocadas em estufa a $103 \pm 2{ }^{\circ} \mathrm{C}$ por 17 horas (BRASIL, 1992). O grau de umidade foi calculado através da expressão:

$$
\begin{aligned}
& U=P i-\frac{P f}{P i} * 100 \\
& \text { Onde: } \\
& \mathrm{U}=\mathrm{Grau} \text { de umidade } \\
& \mathrm{Pi}=\text { Peso inicial } \\
& \mathrm{Pf}=\text { Peso final }
\end{aligned}
$$

\section{Experimentos de Germinação}

Os experimentos foram instalados no Laboratório de Sementes I do CIPEF. A germinação foi realizada em câmara de germinação tipo BOD (modelo NI 1718, 
fabricada pela marca NOVA INSTRUMENTS), utilizando caixas tipo Gerbox $(15 \times 15 \times 3 \mathrm{~cm})$ contendo areia esterilizada por 2 horas a $200^{\circ} \mathrm{C}$ e água destilada, sob temperatura de $30^{\circ} \mathrm{C}$ e fotoperíodo de 16 horas.

Foram testados os seguintes tratamentos para superação da dormência: sem tratamento prévio (Controle); escarificação com ácido sulfúrico P.A. por 5 minutos $\left(\mathrm{H}_{2} \mathrm{SO}_{4}\right)$; imersão em água a $100{ }^{\circ} \mathrm{C}$ por 5 minutos e embebição em água em temperatura ambiente por 24 horas. Para o pau-santo, não se utilizou o tratamento de escarificação em ácido sulfúrico. Posteriormente as sementes foram imersas em solução de hipoclorito de sódio a 5\% por 15 minutos e lavadas com água destilada.

Para ambas as espécies foi utilizado o delineamento experimental inteiramente casualizado (DIC), com quatro repetições de 25 sementes. As avaliações da germinação foram realizadas diariamente por um período de 15 dias. Foram consideradas germinadas as sementes que emitiram radícula. Os dados obtidos foram submetidos a Análise de Variância e, quando observadas diferenças significativas, as médias foram comparadas pelo teste de Tukey a $5 \%$ de significância. As análises estatísticas foram realizadas no software STATISTICA 10.0 (STATSOFT, 2010).

\section{RESULTADOS E DISCUSSÕES}

Os valores $(8,9 \% ; 15 \% ; 9,1 \% ; 11,0 \% ; 6,0 \%)$ observados para o grau de umidade das sementes de canafístula, pau-jacaré, fedegoso, vinhático e pau-santo respectivamente, apresentaram valores similares àqueles já descritos na literatura.

Em sementes de canafístula, OLIVEIRA et al., (2003) encontraram os valores de $8,7 \%$ e $10,2 \%$ para os dois lotes avaliados, sendo esses similares ao valor de $8,9 \%$ encontrado no presente estudo. As sementes de pau-jacaré apresentaram um teor de água de $15 \%$, valor semelhante aos $14,2 \%$ relatado por CHITARRA et al., (2008). Para o fedegoso, o grau de umidade de $9,1 \%$ encontrado se assemelha a $8,7 \%$, valor relatado por POZITANO et al., (2011). Quanto às sementes de vinhático o grau de umidade de $11,0 \%$ é condizente ao valor de $11,4 \%$ descrito por LOPES et al., (2010). SOUZA et al., (2014) verificaram 5\% de umidade em sementes de pau santo, valor inferior aos $6 \%$ descritos no presente trabalho.

Foram observadas diferenças significativas ( $5 \%$ de significância) para a germinação de canafístula, fedegoso, vinhático (Tabela 2), e pau-santo (Tabela 3) em função dos tratamentos pré-germinativos.

TABELA 2. Germinação de sementes de canafístula, pau-jacaré, fedegoso, vinhático e pau-santo submetidas a tratamentos pré-germinativos: controle, escarificação química em ácido sulfúrico concentrado por cinco minutos $\left(\mathrm{H}_{2} \mathrm{SO}_{4}\right)$, água a $100^{\circ} \mathrm{C}$ por cinco minutos (AF) e Embebição em água na temperatura ambiente por 24 horas (EA).

\begin{tabular}{ccccc}
\hline & Canafístula & Pau-jacaré & Fedegoso & Vinhático \\
\hline Controle & $19 \mathrm{~b}$ & $81 \mathrm{a}$ & $5 \mathrm{c}$ & $64 \mathrm{~b}$ \\
$\mathrm{H}_{2} \mathrm{SO}_{4}$ & $72 \mathrm{a}$ & $83 \mathrm{a}$ & $17 \mathrm{a}$ & $85 \mathrm{a}$ \\
$\mathrm{AF}$ & $15 \mathrm{~b}$ & $86 \mathrm{a}$ & $9 \mathrm{~b}$ & $69 \mathrm{~b}$ \\
$\mathrm{EA}$ & $26 \mathrm{~b}$ & $87 \mathrm{a}$ & $2 \mathrm{c}$ & $56 \mathrm{c}$ \\
\hline
\end{tabular}


Médias seguidas da mesma letra na coluna não diferem estatisticamente entre si pelo teste de TUKEY a 5\% de significância.

TABELA 3. Germinação de sementes de pau-santo submetidas a tratamentos pré-germinativos: controle, água a $100^{\circ} \mathrm{C}$ por cinco minutos (AF) e Embebição em água na temperatura ambiente por 24 horas (EA).

\begin{tabular}{cc}
\hline Tratamento & Germinação (\%) \\
\hline Controle & $63 \mathrm{~b}$ \\
AF & $65 \mathrm{~b}$ \\
EA & $96 \mathrm{a}$
\end{tabular}

Médias seguidas da mesma letra na coluna não diferem estatisticamente entre si pelo teste de TUKEY a $5 \%$ de significância.

Dentre os tratamentos utilizados, a escarificação química em ácido sulfúrico por 5 minutos, se mostrou o mais eficiente para promover a germinação em sementes de canafístula, obtendo uma média de $72 \%$. A eficiência da escarificação química indica que as sementes dessa espécie possuem dormência tegumentar. Em trabalhos similares, outros autores destacam a eficiência da escarificação para promover a germinação.

Segundo FILHO et al., (1997), sementes de canafístula escarificadas mecanicamente obtiveram germinação média de $75 \%$, enquanto sementes escarificadas no ácido sulfúrico concentrado por 3 e 12 minutos germinaram 34,2\% e $40,9 \%$ respectivamente, sendo ambos os tratamentos mais eficientes que o controle (11,3\% de germinação). Sementes de canafístula tratadas por 10 minutos em ácido sulfúrico obtiveram germinação média de $37 \%$, enquanto aquelas escarificadas por 20 minutos obtiveram germinação média de $70 \%$ em rolo de papel (PIVETA, 2010).

Para o fedegoso, nenhum tratamento foi eficiente para promover germinação superior a $17 \%$. Este fato pode estar associado à dormência tegumentar mais severa para essa espécie, sendo necessário maiores tempos de imersão em ácido sulfúrico para promover a escarificação do tegumento. MORAES \& CASTRO (2013), verificaram que sementes de fedegoso escarificadas por 15 minutos em ácido sulfúrico apresentaram maior poder germinativo em areia, com média de $79 \%$ de germinação. Segundo LOPES et al., (2012), a imersão de sementes de fedegoso em ácido sulfúrico por tempos superiores a 10 minutos podem promover germinação superior a 80

Ainda de acordo com os resultados, é possível deduzir que o vinhático possui dormência tegumentar, sendo que a escarificação química afetou positivamente em mais de $20 \%$ a germinação quando comparado ao tratamento controle. Esses resultados se contrapõe aos obtidos por CARIONE et al., (2012) cuja escarificação química em $\mathrm{H}_{2} \mathrm{SO}_{4}$ na concentração de $10 \%(\mathrm{v}, \mathrm{v})$ por 10 minutos se mostrou pouco eficiente, promovendo germinação de apenas $45 \%$ das sementes. A provável causa dessa discrepância é a diferença da concentração do ácido utilizado, sendo que maiores concentrações favorecem maior grau de escarificação.

Embora não tenha sido observada diferença significativa para os tratamentos pré-germinativos em sementes de pau-jacaré, a imersão em água quente por 5 minutos e embebição em água por 24 horas, promoveram maior taxa de germinação. Diante disso, ambos os tratamentos podem ser indicados para produção de mudas de vinhático, pois são tratamentos simples e que representam 
baixo custo. Todos os tratamentos ocasionaram valores de germinação em vinhático superior aos 73\% encontrados por SANTOS JUNIOR et al., (2004).

Não foi observada dormência tegumentar para o pau-santo, no entanto a embebição em água por 24 horas favoreceu significativamente a germinação, sendo que sementes previamente embebidas obtiveram média de $96 \%$ de germinação, valor superior aos $65 \%$ e $63 \%$ ocorridos nos tratamentos com água quente e controle respectivamente e ao valor (75\%) encontrado por SOUZA et al., (2014). Em sementes de Cupressuslusitanica mill a embebição em água destilada por 24 horas favoreceu a germinação (XAVIER et al., 2012).

A dormência caracterizada pela impermeabilidade tegumentar já foi relatada em diversas espécies florestais, sendo que os métodos mais indicados para promover a quebra desse tipo de dormência variam em função da espécie e do grau de dormência apresentado. Espécies como Caesalpinia ferrea, Parkinsonia aculeata L., Acacia mearnsii, Dilonix regia, Myrsine parvifolia, Parkia gigantocarpa, Hymenaea courbaril, são alguns exemplos já estudados e que apresentam dormência tegumentar, fazendo-se necessário a aplicação de algum método de escarificação química, térmica ou mecânica para aumentar ou até mesmo promover germinação (ROVERSI et al., 2002; COELHO et al., 2010; OLIVEIRA et al., 2012; LIMA et al., 2013; FREITAS et al., 2013; PEREIRA \& JACOBI, 2014; AGRA et al., 2015).

De modo geral, é possível inferir que as sementes de canafístula, vinhático e fedegoso possuem dormência tegumentar e assim necessitam receber tratamentos pré-germinativos como a escarificação química, favorecendo assim germinação mais homogênea e em maior escala. Embora as sementes de pau-jacaré e pau-santo não apresentam dormência tegumentar, a imersão em temperatura ambiente pode favorecer a embebição, dando início ao processo germinativo.

\section{CONCLUSÕES}

A escarificação química em ácido sulfúrico concentrado é recomendada para superação da dormência tegumentar em sementes de canafístula e vinhático. A embebição em água por 24 horas é indicada para aumentar o poder germinativo de sementes de pau jacaré e pau santo.

\section{REFERÊNCIAS}

AGRA, P.F.M., GUEDES, R.S.,SILVA, M.L.M.,SOUZA, V.C, ANDRADE, L.A., ALVES, D.U. Métodos para superação de dormência de sementes de Parkinsonia aculeata L. Semina: Ciências Agrárias, Londrina, v. 36, n. 3, p. 1191-1202, maio/jun. 2015

ARAÚJO, T.V.; JOAQUIM, W.M.; BARJA, P.R. Técnicas de quebra de dormência e estudo de substratos orgânicos para produção de mudas de leucena. Revista Univap, São José dos Campos, v.18, n.32, dez. 2012.

ARRUDA, E.S.; OLIVEIRA, W.P.; CONCEIÇÃO C.A.; FEIDEIN, A. BORSATO, A.V. Imersão de sementes em água em diferentes temperaturas para superação de dormência em Acacia mangium Willd, para uso em sistemas agroecológicos.

Cadernos de Agroecologia, Corumbá, v. 7, n.2, dez. 2012. 
BASKIN, J.M. \& BASKIN, C.C., LI, X. 2000. Taxonomy, anatomy and evolution of physical dormancy in seeds. Plant Species Biology 15: 139-152.

BEWLEY, J. D.; BLACK, M. Seeds: physiology of development and germination. 2. ed. New York: Plenum press, 1994. 445 p.

BORGES, E.E.L., BORGES, R.C.G., PAULA, N.F., Efeito da temperatura e do estresse hídrico na germinação de sementes de fedegoso (Senna macranthera Collad.) e de Leucaena leucophala (Lam.) Revista Brasileira de Sementes, vol. 19, no 2, p.155-158, 1997.

BRAGA, L.L.; TOLENTINO, G.S.; SANTOS, M.R.; VELOSO, M.D.M; NUNES, Y.R.F. Germinação de Sementes de Plathymenia reticulata Benth. (FabaceaeMimosoideae) sob Influência do Tempo de Armazenamento. Nota Científica. Revista Brasileira de Biociências, Porto Alegre, v.5, supl.2, p.258-260, 2007.

BRASIL. Ministério da Agricultura e Reforma Agrária. Regras para análise de sementes. Brasília: SNDA/DNDV/CLAV, 1992. 365 p.

CARMARGO, F. F.; SOUZA, T. R.; COSTA, R.B. Etnoecologia e etnobotânica em ambientes de Cerrado no Estado de Mato Grosso, INTERAÇÕES, Campo Grande, v. 15, n. 2, p. 353-360, 2014.

CARRIONE, R.M., PACHECO, F.V., PEREIRA, C.R., ALVARENGA, I.C.A., Tratamentos pre germinativos em semente de Plathymenia reticulata Benth. Enciclopédia Biosfera, Centro Científico Conhecer, Goiânia, v.8, n.15; p. 1614, 2012.

CARVALHO, N. M.; NAKAGAWA, J. Sementes: ciência, tecnologia e produção. 5.ed. Jaboticabal: FUNEP, 2012. 590 p.

CHITARRA, J.F., MORI, E.S., NAKAGAWA, J., OHTO, C.T., PINTO, C S., FERNANDES, K. H. P. Época de colheita de sementes de Pau Jacaré Piptadenia gonoacantha (Mart.) Revista Cientifica Eletrônica de Engenharia Florestal, Ano 7, N.12, Agosto. 2008.

FILHO, J.P.L., GUERRA, S.T.M., LOVATO, M.B., SCOTTI, M.R.M.M.L., Germinação de sementes de Senaa macranthera, Senna multijuga e Stryphnodendron polyphyllum. Pesquisa Agropecuária Brasileira, Brasília, v.32, n.4, p 357-361, 1997.

FREITAS, A.R.; LOPES, J.C.; MATHEUS, M.L.; MENGARDA, L.H.; VENANCIO, L.P.; CALDEIRA, M.V.W. Superação de dormência de sementes de jatobá. Pesquisa Florestal Brasileira, Colombo, v.33, n.73, p.85-90, jan/mar. 2013.

HERNÁNDEZ, W.; XAVIER, A.; PAIVA, H.N.; WENDLING, I. Propagação vegetativa do pau jacaré (Piptadenia gonoacantha (Mart.) Macbr.) por estaquia. Revista Árvore, Viçosa, v.36, n.5, p. 813-823, 2012. 
JUNIOR, N.A.S., BOTELHO, S.A., DAVIDE, A.C. Estudo da germinação e sobrevivência de espécies arbóreas em sistema de semeadura direta, visando a recomposição de mata ciliar. Cerne, Lavras, v. 10, n. 1, p. 103-117, 2004.

JÚNIOR, R.A.; MELLO, W.S.; SANTOS, S.R.G.; KOZUSNY-ANDREANI, D.I. Superação da dormência de sementes de três essências florestais nativas. Revista da Universidade Vale do Rio Verde, Três Corações, v.12, n.1, p. 470-479, jan/julho. 2014.

LIMA, J.S., CHAVES, A.P. MEDEIROS, M.A., RODRIGUES, G.S.O., BENEDITO, C.B. Métodos de superação de dormência em sementes de flamboyant (Delonyx regia). Revista Verde, v. 8, n. 1, p. 104 - 109, jan/mar, 2013.

LOPES, J.C., BARBOSA, L.G., CAPUCHO, M.T., Biometria, dormência e viabilidade de sementes de Senna macranthera. Nucleus, v.9, n.2, outubro. 2012.

LOPES, R.M.F., FREITAS, V.L.O., FILHO, J.P.L., Biometria de frutos e sementes e germinação de Plathymenia reticulata Benth. e Plathymenia foliolosa Benth. Revista Árvore, Viçosa-MG, v.34, n.5, p.797-805, 2010.

LORENZI, H. Árvores brasileiras: Manual de identificação e cultivo de plantas arbóreas nativas do Brasil, 6 ed. Nova Odessa: Plantarum, 2014. 368p.

MAYER, A. M.; POLJAKOFF-MAYBER, A. The germination of seeds. Oxford: Pergamon, 1989. 270 p.

MORAES, C.E., CASTRO, K.C., Substratos alternativos para a germinação de sementes de fedegoso (Senna macranthera Collad). Enciclopédia Biosfera, Centro Científico Conhecer - Goiânia, v.9, n.17; p. 2398, 2013.

OLIVEIRA, L. M., FERREIRA, R.A., CARVALHO, M.L.M. Germinação de sementes de Senna multijuga (Rich.) Irwin e Barn, sob diferentes condições de radiação luminosa e temperaturas. Revista Ciência Agronômica, Vol. 34, NO.2 -: 213 - 218, 2003.

PEREIRA, V.J., SANTANA, D.G., LOBO, G.A., BRANDÃO, N.A.L., SOARES, D.C.P., ,2014. Eficiência dos tratamentos para a superação ou quebra de dormência de sementes de Fabaceae. Revista de Ciências Agrárias, 37(2), p.187.

PESSOA, R.C., MATSUOTO, S.N. MORAIS, O.M., VALE, R.S., LIMA, J.M., Germinação e maturidade fisiológica de sementes de Piptadenia viridifolia (Kunth.) Benth relacionadas a estádios de frutificação e conservação pós colheita. Revista Árvore, Viçosa-MG, v.34, n.4, p.617-625, 2010.

PIVETA, G., MENEZES, V.O. PEDROSO, D.C., MUNIZ, M.F.B, WIELEWICKI, A.P., Superação de dormência na qualidade de sementes e mudas: influencia na produção de Senna multijuga (L. C.Rich.) Irwin \& Barneby. Acta Amazonia, Vol 40(2), 281-288, 2010. 
POZITANO, M., ROCHA, S.C.S., Caracterização física e germinação de sementes de senna macranthera. Revista Brasileira de Sementes, vol. 33, no 4 p. 777 - 784, 2011.

RIBEIRO, K. T.; NASCIMENTO, J. S.; MADEIRA, J.A.; RIBEIRO, L. C. Aferição dos limites da Mata Atlântica na Serra do Cipó, MG, Brasil, visando maior compreensão e proteção de um mosaico vegetacional fortemente ameaçado, Natureza \& Conservação - v. 7 - nำ1, p. 30-49, 2009.

SANTOS, J.L., LUZ, I.S., MATSUMOTO, S.N., D’ARÊDE, L.O., VIANA, A. E.S., Superação da dormência tegumentar de sementes de Piptadenia viridifolia (Kunth) Benth pela escarificação química. Biosci. J., Uberlândia, v. 30, n. 6, p. 1642-1651, 2014

SANTOS, L.W.; COELHO, M.F.B.; MAIA, S.S.S.; SILVA, R.C.P.; CÂNDIDO, W.S.; SILVA, A.C. Armazenamento e métodos para a superação de dormência de sementes de mulungu. Semina: Ciências Agrárias, Londrina, v.34, n.1, p. 171-178, jan/fev. 2013.

SILVA, K.B.; MATA, M.F.; BRUNO, R.L.A. Tratamento pré-germinativos para superação da dormência de sementes de Sterculia striata A. St. Hil. Naldin. Semina: Ciências Agrárias, Londrina, v.33, n.3, p. 857-866, maio/jun. 2012.

SOUZA, F.P. Tecnologia de produtos florestais. Rio de Janeiro: Nacional, 1974. 409p.

SOUZA, N.H.; MARCHETTI, M.E.; CARNEVALI, T.O.; RAMOS, D.D.; SCALON, S.P.Q.; SILVA, E.F. Estudo nutricional da canfístula (I): crescimento e qualidade de mudas em resposta à adubação com nitrogênio e fósforo. Revista Árvore, Viçosa, v.37, n.4, p.717-724, 2013.

SOUZA, P.F., NERY, M.C., PIRES, R.M.O., PINTO, N.A.V.D., SOARES, B.C., Caracterização morfológica e composição química de sementes de espécies florestais. Enciclopédia Biosfera, Goiânia, v.10, n.18, p.874, 2014.

STATSOFT, Inc. (2010). STATISTICA (data analysis software system), version 10. www.statsoft.com.

XAVIER, S.A.; FUKAMI, J; MIOTTO, L.C.V.; SOBOTTKA, R.P.; NAKATANI, S.H.; TAKAHASHI, L.S.A.; MACHADO, M.H. Superação da dormência de sementes de Cupressus lusitanica Mill. Semina: Ciências Agrárias, Lodrina, v. 33, n. 3, p. 10411046, maio/jun. 2012. 